\title{
The Impact of Healthcare Reform Plan on the Rate of Vaginal Delivery and Cesarean Section in Shiraz (Iran) in 2015
}

\author{
Faranak Rooeintan ${ }^{1}$, Parviz Aghaei Borzabad ${ }^{2}$, Abbas Yazdanpanah $^{3}$
}

${ }^{1}$ M.Sc., Department of Healthcare Management, Fars Science and Research Branch, Islamic Azad University, Marvdasht Iran

${ }^{2}$ Ph.D., Assistant Professor, Department of Medical Education Management, Cellular and Molecular Research Center, Yasuj University of Medical Sciences, Yasuj, Iran

${ }^{3}$ Ph.D., Assistant Professor, Department of Healthcare Management, Marvdasht Branch, Islamic Azad University, Marvdasht, Iran

\section{Type of article: Original}

\begin{abstract}
Introduction: The uncontrolled increase in the rate of cesarean section is one of the most controversial issues, and is a primary challenge among health policy makers. This study was conducted to examine the impact of the Iranian health evolution plan on vaginal delivery rate and cesarean section.

Methods: This cross-sectional study was carried out in 2014. Maternal health data for 2013 and 2014 were used in this study and changes in vaginal delivery and cesarean section were compared before and after the reform, using t-test and Wilkinson test.

Results: According to the findings of this study, $64.7 \%$ of deliveries in 2013 were performed using cesarean section while it was $58.6 \%$ in $2014(\mathrm{p}=0.772)$, of which no significant changes were observed. In addition, the percentage of vaginal delivery in 2013 and 2014 were $35.3 \%$ and $41.4 \%$ respectively $(p=0.00)$, so a significant increase was found for vaginal delivery.

Conclusion: Healthcare reform has led to an increase in the number of vaginal deliveries in hospitals affiliated to Shiraz University of Medical Sciences (SUMS). Due to the limited number of hospitals adhering to the healthcare reform plan to increase vaginal delivery (using private midwife and implementing painless delivery), the reform for decreasing the cesarean rate was not effective enough.

Keywords: Vaginal delivery, Cesarean section, Healthcare reform plan
\end{abstract}

\section{Introduction}

Health is one of the most important dimensions of socioeconomic development in each society. One of the most important health indicators in each country is maternal health $(1,2)$. Today, the choice of cesarean section is one of the controversial issues in the health system of countries throughout the world (3). Because of its side effects and insensitivity, tendency for women to go ahead with vaginal delivery has decreased. Due to the naturalness of vaginal delivery, the most favoured method of delivery is vaginal delivery (4). Different factors such as the pregnant women's awareness regarding vaginal delivery, lack of awareness about the complications of cesarean section, fear of vaginal delivery, being encouraged by physician and the reduced role of midwives in training, have led to increased willingness of mothers for cesarean section (5). Moreover, other factors such as maternal age, progress in surgical techniques, social and economic factors, supplemental insurance and health insurance coverage, lack of experienced midwives and lack of training in pregnancy period, have led to decreased willingness of vaginal delivery (6). In recent years, according to the ministry of health data, the rate of cesarean section in Iran has increased by 40 to $60 \%$ which is three times more than global standards (7). Although, according to WHO

\section{Corresponding author:}

Assistant Professor Dr. Parviz Aghaei Borzabad, Department of Medical Education Management, Cellular and Molecular Research Center, Yasuj University of Medical Sciences, Yasuj, Iran.

Tel: +989171439539, Email: aghaieparv@gmail.com

Received: June 01, 2016, Accepted: July 04, 2016, Published: October 2016

iThenticate screening: July 01, 2016, English editing: August 20, 2016, Quality control: September 04, 2016

(C) 2016 The Authors. This is an open access article under the terms of the Creative Commons Attribution-NonCommercialNoDerivs License, which permits use and distribution in any medium, provided the original work is properly cited, the use is non-commercial and no modifications or adaptations are made. 
guidelines, the rate of cesarean section should be 5-15\% (8). Complications of unnecessary cesarean section affect the health of the mother and children and increases economic burden. So, elective cesarean section is one of the most important challenges of health systems. It is essential for governments to perform effective changes in maternal health and also decrease the rate of elective cesarean section (9). The uncontrolled increase in the rate of unnecessary cesarean section is a major problem in the health system of Iran (8). Hence, a program called the Healthcare Evolution Plan has been implemented in Iran since May, $4^{\text {th }}, 2014$ in order to fulfill the goals of the WHO. (Specific goals include health, fairness in financial contribution and meeting the non-treatment expectations of the public). One of the most important packages of this plan was to promote vaginal delivery (10). It was expected that by the end of 2014 the rate of cesarean section would be reduced by as much as $10 \%$ (11). Iran was the second highest country in the world to have caesarian section at the start of the project (8). WHO guidelines emphasize that countries must improve maternal and infant health, by reducing the rate of cesarean section. The present study was conducted to assess the impact of healthcare reform plans on the rate of vaginal delivery and cesarean section. Furthermore, the frequency and deviation of deliveries in public and private hospitals of provincial capitals were compared. In order to gain suitable strategies for policy makers in Shiraz University of Medical Sciences, a comparison was made on the statistics related to 2013 (one year before implementation of project) and 2014 (one year after implementation of project).

\section{Material and Methods}

This was a descriptive-analytic cross-sectional study. The main aim of this study was to examine the impact of the healthcare reform plan on the number of vaginal deliveries and cesarean sections, and its impact on the government adopted policies toward increasing vaginal delivery. The rate of vaginal delivery and cesarean section in public and private hospitals were compared. First, descriptive statistics, related to the investigated period (2013-2014) were mentioned based on the number and percentage. Then the normality in the data was tested using KolmogorovSmirnov test. According to data distribution, the statistical assumptions had the conditions of using parametric and non-parametric tests. Finally, paired-samples t-tests and Wilcoxon tests were used for assessing the hypotheses. Data collection was conducted with the authorization from the vice chancellor for research. The accurate date registration, honesty in data analysis, presenting correct statistics according to the collected data, publishing the results in a simple language and presenting them to the authorities for correct decision and policy making, were taken into consideration and emphasized by the researcher. STATA software V 13.1 was used for analyzing data.

\section{Results}

The average number of vaginal delivery in 2013 was less than the average number of vaginal delivery in 2014 (Table 1), it revealed that there is a significant difference between the number of vaginal delivery in 2013 and 2014 $(\mathrm{p} \leq 0.01)($ Table 2$)$.

Table 1. The rate and percentage of vaginal delivery and cesarean section in 2013 and 2014

\begin{tabular}{|l|l|l|l|l|l|}
\hline \multirow{2}{*}{ Year } & \multicolumn{2}{|l|}{ Vaginal delivery } & \multicolumn{2}{l|}{ Cesarean section } & \multirow{2}{*}{ Total } \\
\cline { 2 - 5 } & $\mathrm{n}$ & $\%$ & $\mathrm{n}$ & $\%$ & \\
\hline 2013 & 23361 & 35.3 & 42871 & 64.7 & 66232 \\
\hline 2014 & 30560 & 41.4 & 43319 & 58.6 & 73879 \\
\hline Total & 53921 & & 86190 & & \\
\hline
\end{tabular}

Table 2. Comparing the difference of means of indicators at a glance

\begin{tabular}{|l|l|l|l|l|}
\hline Variables & Type of test & $\begin{array}{l}\text { Test } \\
\text { name }\end{array}$ & $\begin{array}{l}\text { Test } \\
\text { statistics }\end{array}$ & $\begin{array}{l}\text { p- } \\
\text { value }\end{array}$ \\
\hline Vaginal delivery in 2013-vaginal delivery in 2014 & Non-parametric & $\mathrm{z}$ & $-5.695 \mathrm{a}$ & 0.000 \\
\hline Cesarean section in 2013-cesarean section in 2014 & Non-parametric & $\mathrm{z}$ & $-0.290 \mathrm{a}$ & 0.772 \\
\hline $\begin{array}{l}\text { Vaginal delivery in 2013-vaginal delivery in 2014- private } \\
\text { hospitals }\end{array}$ & Non-parametric & $\mathrm{z}$ & $-3.480 \mathrm{a}$ & 0.001 \\
\hline $\begin{array}{l}\text { Vaginal delivery in 2013-vaginal delivery in 2014 public } \\
\text { hospitals in center of province }\end{array}$ & Parametric & $\mathrm{t}$ & -1.643 & 0.019 \\
\hline $\begin{array}{l}\text { Vaginal delivery in 2013-vaginal delivery in 2014 public } \\
\text { hospitals other than center of province }\end{array}$ & Parametric & $\mathrm{t}$ & -3.943 & 0.001 \\
\hline Painless delivery in 2013- painless delivery in 2014 & Parametric & $\mathrm{t}$ & -0.609 & 0.652 \\
\hline Delivery by midwife in 2013- delivery by midwife in 2014 & Parametric & $\mathrm{t}$ & -0.987 & 0.428 \\
\hline
\end{tabular}


By observing the average number of deliveries, it was concluded that the Health Evolution Plan was effective in increasing the number of vaginal delivery (Table 1). However, the number of cesarean sections in 2014 had decreased in comparison to 2013 (Table 1), was not significant $(\mathrm{p}=0.772$ ) (Table 2). In this study, the nulliparous cesarean sections were not separated from the repeated ones. Moreover, different indications for cesarean section were not considered. By observing the average number of deliveries, it is obvious that the healthcare reform plan has been influential in increasing the number of vaginal delivery. In addition, implementing healthcare reform has increased the number of vaginal delivery in public hospitals and decreased it in private hospitals. Statistical analysis indicated that there was a significant difference between implementing the healthcare reform plan and the number of vaginal deliveries in public hospitals $(p=0.019)$ (Table 2$)$. This means that implementing the healthcare reform plan has been influential in public hospitals. The findings showed that there was not a significant difference between implementing the healthcare reform plan and the number of painless deliveries $(\mathrm{p}=0.652)$. Despite the increasing number of painless deliveries in 2014, (due to the limited number of hospitals contributing in painless delivery), no significant difference could be seen and it could be concluded that the healthcare reform plan was not influential in this aspect. This study also revealed that there was not a significant difference between implanting the healthcare reform plan and the number of deliveries carried out by midwives $(p=0.428)$. Despite the increasing number of deliveries done by midwives in 2014, due to the limited number of hospital using private midwives or lack of equipment for physiological delivery, no significant differences were found and the healthcare reform plan was not influential.

\section{Discussion}

Promotion of vaginal delivery and reducing the rate of cesarean section are the primary objectives of the healthcare reform plan in Iran. This plan started throughout the country in May 2014. Various surveys have shown that the main reason of cesarean section is the repeated cesarean (12). Hence, proper planning is needed to reduce the number of cesarean sections in nulliparous women in order to prevent repeated cesarean sections in future. Fear of vaginal delivery, mother's age and physician's recommendations are the most influential factors which encourage mothers to undergo cesarean section. So, holding consultation sessions before and during pregnancy could help mothers to choose the best method of delivery (13). Furthermore, familiarity with delivery room, staffs, equipment, analgesia, presence of visitors and making the delivery room pleasant (14) are the factors reducing maternal anxiety, and aid the mother in choosing the best method of delivery. Based on the instructions of mother-friendly hospitals, hospitals are obliged to set up physiological delivery rooms (5). Training staff and physicians, limiting the use of elective cesarean section and cross section on uterus for possible vaginal delivery after cesarean section, were other factors which had influenced mothers' choice and it had increased the number of vaginal delivery, and had decreased the number of cesarean section (15). After the implementation of the health evolution plan, due to increase in the number of vaginal delivery, the government decreased the franchise of vaginal delivery to zero. It was expected that with the zero franchise of vaginal delivery, the number of patrons in public hospitals would increase and the number of vaginal deliveries would increase too. The results of the present study showed that the percentage and number of vaginal delivery in public hospitals has been increased. However, implementation of healthcare reform not only decreased the number of vaginal delivery in private hospitals but also increased the number of cesarean section in those hospitals. The main reason of decline in vaginal delivery in private hospitals was making vaginal delivery free in public hospitals and physicians' limitations for cesarean section in public hospitals. Fear was the most important reason - and also the main reason for nonmedical demand of mothers for elective cesarean section (11). Increase in the number of painless delivery was another policy adopted by the ministry of health to promote vaginal delivery. Despite the increased number of painless deliveries after the reform, only two hospitals carried out painless deliveries. So, the number of samples for this type of delivery was little, and no significant difference was found between implementing healthcare reform and painless delivery. It can be predicted that the development of painless delivery facilities in other centers not only increase the number of vaginal delivery, but also improve equity in access of painless delivery. Another reason for mothers' willingness for cesarean section is the fear of maternity units and lack of visitors. By the presence of trained visitors and providing the facilities with physiological delivery in hospitals, the percentage of vaginal delivery could be increased (16). Using midwives and making contracts with them in hospitals is another adopted policy to promote vaginal delivery (17). Despite the increased number of deliveries performed by midwives in 2014, in comparison with 2013, the limited number of hospitals having the facilities for vaginal delivery, and private midwives, led to the fact that there was no significant difference between the healthcare reform plan and delivery by midwife. With the launch of physiological delivery in all hospitals and benefiting from private midwives who have private offices, the number of vaginal delivery can be increased. In 2014, Tabrizi et al. also evaluated the health evolution plan. According to their nationwide study, the rate of cesarean section was $56.1 \%$ in 2013 , and in the first quarter of the project it had been 
decreased to $53.6 \%$. Besides this, the rate of cesarean section in public hospitals decreased from $47 \%$ to $42 \%$ after the reform however, the rate of cesarean section in private hospitals was $88 \%$. It was revealed that the highest rate of decrease in cesarean section was related to public hospitals (5.3\%). Other hospitals such as social security hospitals $(0.2 \%)$, and private hospitals $(0.4 \%)$ did not have any significant decrease. It indicated that the success of this project is in the public hospitals with more slope, thus more intervention is needed in private hospitals (18). In 2013 Afshari et al. carried out another study to show the rate of cesarean section in the first eight months of implementing the healthcare reform plan in the hospitals affiliated to Isfahan University of Medical Sciences. They found that cesarean section had decreased by $12.5 \%$ (19). Finally, it can be concluded that implementation of the healthcare reform plan has been effective on the rate of vaginal delivery but it did not have such influence on private hospitals. According to the negative impact of the healthcare reform plan in the private hospitals, it is suggested to increase tariffs of basic and supplementary insurance for delivery in private hospitals (20). Furthermore, in a number of private hospitals there are no facilities for vaginal delivery. As a result of equipping these centers with delivery rooms and vaginal delivery facilities, developing physiologic delivery rooms, performing painless delivery, having contract with midwives, the number and percentage of vaginal delivery would be increased. It is suggested to determine the causes of cesarean section and separate the nulliparous cesarean section from repeated cesarean section in the study (21). This study had some limitations. First, data for painless delivery and delivery by midwives in some centers were not available. Second, we were not able to compare the reform with other studies because no similar reforms had been implemented in other countries.

\section{Conclusions}

One of the main aims of the health sector evolution plan in Iran was to decrease cesarean section and increase vaginal delivery. Our study showed that however the number of vaginal deliveries has increased during the reform, cesarean section has not been changed after the reform. Policy makers must find solutions to decrease cesarean section in the health care private sector. In this article, some solutions are proposed. For future studies it is suggested that other effects of the reform on Iran health care delivery should be tested.

\section{Acknowledgments:}

Hereby, we sincerely thank the research department of Marvdasht Islamic Azad University, MR Sajad Delavari and Head of Maternal Health Affairs in Shiraz University of Medical Sciences (Mrs. Shafie) who helped us with valuable guidance.

\section{Conflict of Interest:}

There is no conflict of interest to be declared.

\section{Authors' contributions:}

All authors contributed to this project and article equally. All authors read and approved the final manuscript.

\section{References:}

1) Rad EH, Tavakkoli M, Moghadamnia MT, Ghanbari A. Fertility and Minority: A Study in Two Provinces of Iran Using Matching Estimator Technique. J Immigr Minor Health. 2016; 18(3): 660-5. doi: 10.1007/s10903-015-0239-4. PMID: 26362670.

2) Hatam N, Tourani S, Homaie Rad E, Bastani P. Estimating the Relationship between Economic Growth and Health Expenditures in ECO Countries Using Panel Cointegration Approach. Acta Med Iran. 2016; 54(2): 102-6. PMID: 26997596, PMCID: PMC26997596.

3) Tollånes MC, Moster D, Daltveit AK, Irgens LM. Cesarean section and risk of severe childhood asthma: a population-based cohort study. J Pediatr. 2008; 153(1): 112-6. doi: 10.1016/j.jpeds.2008.01.029. PMID: 18571547.

4) Kadivar MR, Yarmohammadi H, Mirahmadizadeh AR, Vakili M, Karimi M. Prevalence of iron deficiency anemia in 6 months to 5 years old children in Fars, Southern Iran. Med Sci Monit. 2003; 9(2): 100-4. PMID: 12601296.

5) Yazdizadeh B, Nedjat S, Mohammad K, Rashidian A, Changizi N, Majdzadeh R. Cesarean section rate in Iran, multidimensional approaches for behavioral change of providers: a qualitative study. BMC Health Serv Res. 2011; 11(1): 159. doi: 10.1186/1472-6963-11-159. PMID: 21729279 , PMCID: PMC3146409.

6) Sefiddashti SE, Rad EH, Mohamad A, Bordbar S. Female Labor Supply and Fertility in Iran: A Comparison Between Developed, Semi Developed and Less Developed Regions. Iran J Public Health. 2016; 45(2): 186-93. 
7) Badakhsh MH, Seifoddin M, Khodakarami N, Gholami R, Moghimi S. Rise in cesarean section rate over a 30-year period in a public hospital in Tehran, Iran. Arch Iran Med. 2012; 15(1): 4-7. doi: 012151/AIM.004. PMID: 22208435.

8) Hosseini L, Iran-Pour E, Safarinejad MR. Sexual function of primiparous women after elective cesarean section and normal vaginal delivery. Urol J. 2012; 9(2): 498-504. PMID: 22641494.

9) Shariat M, Majlesi F, Azari S, Mahmoudi M. Cesaren Sestion In Maternity Hospitals Intehran, Iran. Payesh. 2002; 1(3): 5-10.

10) Rad EH, Karyani AK, Zandian H. Access and necessity for road emergency sites. Trauma monthly. 2016; e27577. doi: 10.5812/traumamon.27577.

11) Larijani B, Majdzadeh R, Delavari AR, Rajabi F, Khatibzadeh S, Esmailzadeh H, et al. Iran's health innovation and science development plan by 2025. Iranian J Publ Health. 2009; 38(1): 13-6.

12) Arsalani G, Sajjadi H, Rafiey H, Habbibpor K. Maternal Health, Quality of Life and Their Relationship in Iran's Provinces. Social Welfare Quarterly. 2014; 13(51): 25-41.

13) Mohamadzadeh DM, Haqaee, DH. Cesarean section or vaginal delivery? Tehran: Tolooe Danesh. 2011.

14) Askarian M, Memish ZA, Khan AA. Knowledge, practice, and attitude among Iranian nurses, midwives, and students regarding standard isolation precautions. Infect Control Hosp Epidemiol. 2007; 28(2): 241-4. doi: 10.1086/510868. PMID: 17265414.

15) Simbar M, Ghafari F, Zahrani ST, Majd HA. Assessment of quality of midwifery care in labour and delivery wards of selected Kordestan Medical Science University hospitals. Int J Health Care Qual Assur. 2009; 22(3): 266-77. doi: 10.1108/09526860910953539. PMID: 19537187.

16) Farokhi F, Khadivzadeh T. Quality assessment of midwives performance in prenatal cares in urban health centers in Mashhad, Iran. 2008.

17) Rad EH, Rezaei S, Fallah R. Physician labor participation and unemployment rate in Iran. Shiraz EMedical Journal. 2015; 16(4).

18) Tabrizi J, Maleki A, Yadolahi B, Javadi R. Successfulness of vaginal delivery promotion. The congress of criticizing the government in health field. Tehran 2014.

19) Afshari S, Zadeh J, Yadegarfar Q, Soleimani F. The impact of healthcare reform plan on the rate of secarean section in hospitals affilited to Isfan University of medical Scinces. The international congress on consistent development. Tehran 2014.

20) Rezaei S, Bazyar M, Fallah R, Chavehpour Y, Rad EH. Assessment of Need and Access to Physician and Hospital Beds: A Cross Sectional Province Based Study in Iran. Shiraz E-Medical Journal. 2015; 16(6).

21) Ivan B, Kiani R, Farmalakuti J. Cesarean section or vaginal delivery? which one is better? Differences, pro and cones. The international congresss of vaginal delivery Tehran: Tehran; 2007. 